\title{
GERMINAÇÃO E VIGOR DE SEMENTES DE Brachiaria brizantha cv. Marandú EM FUNÇÃO DO TEMPO DE MISTURA COM URÉIA
}

Eduardo do Valle Lima'; José Cláudio Sousa Tavares²; Patrícia da Silva Leitão-Lima1; Daniel Pereira Pinheiro ${ }^{1}$; Welliene Moreira dos Santos ${ }^{3}$

${ }^{1}$ Universidade Federal Rural da Amazônia - UFRA, e-mail: eduardo.valle_lima@yahoo.com.br, patleitao@yahoo.com.br, daniel_pinh@hotmail.com

${ }^{2}$ Secretaria de Produção Rural de Parauapebas - PA, e-mail: joseclaudio.tavares@ yahoo.com.br

${ }^{3}$ Universidade Federal de Minas Gerais - UFMG, e-mail: welliene@ yahoo.com.br

\section{RESUMO}

Objetivou-se estudar o efeito da mistura do adubo uréia com sementes de Brachiaria brizantha em sua germinação e vigor. As variáveis avaliadas foram teor de água, germinação, primeira contagem, condutividade elétrica, emergência e índice de velocidade de emergência. Houve efeito significativo em todas as variáveis. Com o transcorrer do tempo de mistura com o fertilizante, o teor de água e a condutividade elétrica das sementes aumentaram. Ao mesmo tempo, observou-se diminuição da percentagem de germinação, da primeira contagem, da emergência e do índice de velocidade de emergência. Concluiu-se que, quanto maior o tempo de contato das sementes de $B$. brizantha com o fertilizante uréia, menor será a taxa de germinação e vigor das sementes.

Palavras-chave: Brachiaria, fertilizante nitrogenado, sistema de integração lavoura-pecuária

\section{GERMINATION AND VIGOR OF Brachiaria brizantha cv. Marandú SEEDS IN FUNCTION OF TIME OF MIXTURE WITH UREA}

\begin{abstract}
The aim of the study was to evaluate the effect of mixture of the fertilizer urea with Brachiaria brizantha seeds on its germination and vigor. Variables evaluated were water content, germination, first count, electrical conductivity, emergence, and emergence velocity index. There was a significant effect for all variables. As time of mixture with the fertilizer increased, seed water content and electric conductivity also increased. At the same time, germination, first count, emergence, and emergence velocity index decreased. One observed that the damage to the seed germination and vigor increased as contact time with ureia fertilizer increased.
\end{abstract}

Keywords: Brachiaria, nitrogen fertilizer, agriculture livestock farming integration

\section{INTRODUÇÃO}

Maior atenção deve ser dada na formação de pastagens, pois o tamanho reduzido das sementes de $B$. brizantha, aproximadamente de $2,0 \mathrm{~mm}$, dificulta sua distribuição uniforme no espaçamento préestabelecido e a consequente população ideal de plantas (LIMA et al., 2000). A utilização de semeadora com regulagem precisa, e apropriada para proceder a distribuição isolada de sementes e fertilizantes, é indispensável. Entretanto, a maioria dos produtores não possui semeadora-adubadora com regulagem especifica para sementes pequenas (LIMA et al., 2012).

Pode-se lançar mão da utilização de semeadoras empregadas para sementes 
maiores (feijão e milho), desde que as sementes da forrageira sejam misturadas ao fertilizante, servindo o mesmo como via de transporte e distribuição na semeadura, ao mesmo tempo em que se realiza a adubação de plantio (LIMA et al., 2000). Em trabalho clássico de Bacchi (1974) foi demonstrada a implantação de pastagem a partir da mistura prévia de sementes com fertilizante fosfatado. Esta prática antiga utilizada na formação de pastagens, além da mistura de sementes com fertilizantes superfosfato simples ou superfosfato triplo (LIMA et al., 2009), atualmente também emprega sementes misturadas em formulados de nitrogênio-N + fósforo- $\mathrm{P}_{2} \mathrm{O}_{5}+$ potássio-KCl (NPK) (LIMA et al., 2010).

A mistura de sementes do gênero Brachiaria com o adubo mineral é uma prática que vem sendo utilizada não só na renovação de pastagens, mais também na implantação da integração lavoura-pecuária (LIMA et al., 2012).

Deste modo, a mistura do NPK com as sementes de espécies forrageiras deve ter atenção especial, por constituir-se em uma das bases para a implantação do sistema de integração lavoura-pecuária (AIDAR; KLUTHCOUSKI, 2003; MATEUS et al., 2007; LIMA et al., 2010). A integração lavoura-pecuária busca agregar inovações tecnológicas ao sistema de produção e recuperar solos degradados (FOLONI et al., 2009), alternando em um mesmo ano e numa mesma área o cultivo de forrageiras anuais ou perenes a serem utilizadas para a produção de carne e/ou leite com culturas destinadas à produção de grãos (MOREIRA et al., 2012). Apesar do contato direto das sementes com o adubo ser prejudicial à germinação e ao desenvolvimento inicial da espécie forrageira, destaca-se a semeadura consorciada de culturas de grãos, notadamente o milho, com a espécie $B$. brizantha, em que as sementes da gramínea forrageira são frequentemente misturadas ao fertilizante NPK e depositadas nas linhas de semeadura da cultura produtora de grãos (FOLONI et al., 2009). Essa prática de mistura de sementes de forrageira com adubo químico mineral granulado apresenta na literatura técnica e científica informações imprecisas. Segundo Raij et al. (1997), para a formação de pasto com gramíneas, devem-se distribuir os adubos com $\mathrm{N}$ e $\mathrm{K}$ separados das sementes, sendo que se houver necessidade de aplicar apenas $\mathrm{P}$, a mistura pode ser feita, no máximo à véspera do plantio.

Em função da ocorrência de efeitos depressivos às sementes devido ao período de contato com os fertilizantes, Soratto et al. (2003) sugerem a semeadura imediata após a mistura. Com semeadura imediata após a mistura, utilizando semeadora-adubadora manual conhecida como matraca, Lima et al. (2012) obtiveram sucesso na implantação de pastagem a partir da mistura de NPK 10-2820 com semente comercial de B. brizantha.

Todavia, Aidar e Kluthcouski (2003), em integração lavoura-pecuária, recomendam que a mistura de sementes de braquiária com NPK pode perdurar por até $36 \mathrm{~h}$, sem causar prejuízos na formação da pastagem. Mateus et al. (2007) verificaram que a emergência das plântulas de $B$. brizantha não é afetada se for realizada a mistura com fertilizantes químicos NPK até 96 horas antes da semeadura. Em contrapartida, Lima et al. (2010) observaram que a qualidade fisiológica das sementes de $B$. brizantha $\mathrm{cv}$. Marandú foi afetada seriamente quando a mistura com NPK 4-14-8 ocorreu em intervalos superiores a $12 \mathrm{~h}$.

Uma perspectiva ligada a integração lavoura-pecuária, refere-se a possibilidade de implantar o referido sistema semeando-se normalmente a cultura principal junto com a adubação fosfatada e potássica de plantio, deixando-se a adubação de cobertura com uréia para ser feita misturada com as sementes de $B$. brizantha. No entanto, a maioria dos estudos não avalia os efeitos do $\mathrm{N}$ sobre a germinação e vigor das sementes (SANGOI et al., 2009; DAN et al., 2011; 
JANEGITZ; HERMANN, 2011). Dessa forma, o presente trabalho teve como objetivo estudar o efeito de tempos de mistura do adubo uréia, com sementes de Brachiaria brizantha cv. Marandú, avaliando a germinação e o vigor, visando a implantação do sistema de integração lavoura-pecuária.

\section{MATERIAL E MÉTODOS}

O trabalho foi realizado em laboratório e em viveiro com $50 \%$ de sombreamento, no ano de 2006, na cidade de Parauapebas - PA.

As sementes de $B$. brizantha cv. Marandú foram adquiridas em embalagem comercial, hermeticamente fechada, pertencentes ao mesmo lote e com valor cultural igual a $32 \%$, apresentando-se dentro do prazo de validade. Assim, realizou-se a separação manual das sementes puras viáveis (SPV), definindo-se a quantidade de $5 \mathrm{~kg} \mathrm{ha}^{-}$ ${ }^{1}$ das mesmas para semeadura (EMBRAPA, 2004).

A quantidade de adubo para a mistura com as sementes foi definida em $40 \mathrm{~kg} \mathrm{ha}^{-1}$ de $\mathrm{N}$ (RAIJ et al., 1997), o que correspondeu a $88,9 \mathrm{~kg} \mathrm{ha}^{-1}$ de Uréia. Portanto, a proporção da mistura utilizada foi de 4,5 $\mathrm{kg}$ de Uréia para cada $0,25 \mathrm{~kg}$ de SPV.

Antes da mistura foi retirada uma amostra de sementes correspondente ao tratamento controle (sem contato com a Uréia), sendo que o restante das sementes puras viáveis foi misturado homogeneamente ao fertilizante granulado. Posteriormente, a mistura foi acondicionada em uma única embalagem plástica fechada e mantida sob temperatura máxima de $28,4^{\circ} \mathrm{C}$ e média de temperatura mínima de $26,3^{\circ} \mathrm{C}$ durante o transcorrer do experimento. A mistura não foi posta em câmara para armazenamento de sementes, a fim de simular a ação do produtor a campo, onde na prática tem se verificado que, após a mistura adubo + sementes, o volume que não couber na semeadora para plantio imediato é acondicionado temporariamente nos próprios sacos dos fertilizantes até o momento da semeadura. $\mathrm{O}$ fechamento dos sacos se dá pelo fato de facilitar o transporte dos mesmos do local de mistura até a área de plantio.

Decorrido os diferentes tempos de mistura preestabelecidos, foram retiradas, aleatoriamente, $200 \mathrm{~g}$ da mistura para cada tempo de contato, totalizando nove alíquotas, além da testemunha com $200 \mathrm{~g}$ de sementes não misturadas ao adubo. Cada alíquota de $200 \mathrm{~g}$ foi dividida em duas porções iguais, sendo que em $100 \mathrm{~g}$ separou-se de forma manual, com a utilização de pinças e pincéis, as sementes dos adubos, para as determinações de teor de água das sementes, germinação e condutividade elétrica no laboratório. Paralelamente, na outra porção de $100 \mathrm{~g}$ da mistura, as sementes também foram separadas manualmente do adubo, sendo submetidas a determinações de emergência e índice de velocidade de emergência no viveiro.

Determinou-se o teor de água das sementes, pelo método da estufa a $105^{\circ} \mathrm{C}$, com variação de $\pm 3^{\circ} \mathrm{C}$, durante $24 \mathrm{~h}$ (BRASIL, 1992). Realizou-se o teste padrão de germinação segundo Brasil (1992), sendo regulada câmara germinadora do tipo BOD para um período de $8 \mathrm{~h}$ diárias com temperatura de $35^{\circ} \mathrm{C}$, e um período de $16 \mathrm{~h}$ com temperatura a $25^{\circ} \mathrm{C}$, sem luz. Após sete dias, realizou-se a primeira contagem de germinação e após 21 dias da semeadura, realizou-se a contagem final (BRASIL, 1992). Foi também efetuada a determinação da condutividade elétrica das sementes, efetuando-se a leitura do exsudato das sementes contido em água por meio de um condutivímetro, para expressão do valor em $\mu$ $\mathrm{S} \mathrm{cm}^{-1} \mathrm{~g}^{-1}$ (AOSA, 1983).

Foram semeadas manualmente, 50 sementes, com o uso de pinças, em sacos plásticos de $2 \mathrm{~L}$, preenchidos com amostras de terra retiradas da camada arável $(0-20 \mathrm{~cm})$ de um Argissolo Amarelo (EMBRAPA, 
2006). Este apresentava os seguintes atributos químicos: $\mathrm{pH}\left(\mathrm{H}_{2} \mathrm{O}\right)=5,33$; M.O. = 29,85\%; $\mathrm{P}=1,18 \mathrm{mg} \mathrm{dm}^{-3} ; \mathrm{H}+\mathrm{Al}=44,4 \mathrm{mmol}_{\mathrm{c}} \mathrm{dm}^{-3}$; $\mathrm{K}$, Ca e Mg trocáveis = 2,7; 40,4; 12,4 mmol $_{\mathrm{c}}$ $\mathrm{dm}^{-3}$, respectivamente; $\mathrm{SB}=55,5 ; \mathrm{CTC}=$ 99,9 mmol $_{\mathrm{c}} \mathrm{dm}^{-3} ; \mathrm{V} \%=55,6$. Os sacos plásticos foram mantidos sob $50 \%$ de sombreamento, em função das condições de elevadas temperaturas na Amazônia, conservando-se a umidade da terra por meio de regas diárias. Efetuou-se a primeira contagem sete dias após a semeadura, obtendo-se a percentagem de emergência. Posteriormente, realizaram-se contagens diárias do número de plântulas emergidas, efetuando-se a determinação do índice de velocidade de emergência, de acordo com a fórmula apresentada a seguir (Maguire, 1962): $\mathrm{IVE}=\mathrm{N}_{1} / \mathrm{D}_{1}+\mathrm{N}_{2} / \mathrm{D}_{2}+\ldots+\mathrm{N}_{\mathrm{n}} / \mathrm{D}_{\mathrm{n}}$, onde $\mathrm{N}_{1}, \mathrm{~N}_{2}, \mathrm{~N}_{\mathrm{n}}=$ número de plântulas emergidas no $1^{\circ}, 2^{\circ}$ e $n$ números de dias após a implantação do teste até a estabilização; $\mathrm{D}_{1}$, $\mathrm{D}_{2}, \mathrm{D}_{\mathrm{n}}=$ número de dias após a implantação do teste.

O delineamento experimental utilizado foi o inteiramente casualizado, com 4 repetições. Os tratamentos foram constituídos com os seguintes tempos de mistura $(0,3,6,12,24,36,48,72,96$ e 120 horas) de sementes de Brachiaria brizantha cv. Marandú com o fertilizante granulado Uréia. Foram realizadas análise de variância e aplicação do teste $F$, sendo as médias comparadas pelo teste de Tukey a 5\%. Também foram efetuadas análises de regressão polinomial pelo teste $\mathrm{F}$.

\section{RESULTADOS E DISCUSSÃO}

Verifica-se (Tabela 1) que para todas as variáveis estudadas houve diferença significativa entre os tratamentos empregados.

Da mesma forma, Dan et al. (2011), avaliando os efeitos dos tempos de mistura da uréia com sementes de Brachiaria ruziziensis na qualidade fisiológica das sementes, constataram que com o aumento do tempo de contato com o fertilizante, o teor de água e a condutividade elétrica das sementes aumentaram consideravelmente, enquanto observou-se diminuição da porcentagem de germinação, da primeira contagem, da emergência e do índice de velocidade de emergência.

Para a porcentagem final de germinação e primeira contagem, constatouse que quando as sementes de $B$. brizantha foram utilizadas sem contato com 0 fertilizante, os maiores percentuais para estas variáveis foram obtidos em relação aos demais tratamentos. A partir de 48 horas de contato das sementes com a uréia, houve redução drástica da germinação (Tabela 1).

Esse efeito pode ser melhor observado (Figura 1) pela queda substancial na primeira contagem e germinação a partir do momento em que as sementes de $B$. brizantha foram mantidas em contato com a uréia durante o transcorrer do tempo. Resultado similar foi obtido por Mateus et al. (2007), também trabalhando com semente de $B$. brizantha cv. Marandú misturada ao fertilizante uréia. Estes autores observaram que, em condições de laboratório, houve um decréscimo na germinação com o aumento do período de contato da semente com o adubo.

Os efeitos negativos da uréia sobre a germinação das sementes de $B$. brizantha foram mais evidentes em tempos de armazenamento superiores a 48 horas (MATEUS et al., 2007). Comportamento semelhante foi apresentado por Dan et al. (2011), sendo que em intervalos superiores a $16 \mathrm{~h}$, houve redução significativa no total de plântulas normais e o tempo de mistura inferior a 16 h não influenciou na germinação, quando comparado aos resultados obtidos pela testemunha (sem fertilizante), sugerindo que existem diferentes graus de tolerância entre as espécies.

Fica evidente a necessidade de se conhecer as características físico-químicas do adubo e seu comportamento em mistura com 
as sementes. A redução gradual da germinação e primeira contagem em função da mistura de sementes com a uréia, deve-se ao fato de que este adubo apresenta alta higroscopicidade (MELLO, 1987; ALCARDE et al., 1989; ALCARDE et al., 1992), juntamente com o seu efeito tóxico, devido a alta concentração do sal nitrogenado junto as sementes (AGOSTINETTO et al., 2000; SILVA et al., 2002).

Esta tendência em absorver água em função da umidade relativa do ar é característica inerente dos fertilizantes nitrogenados, notadamente a uréia (ALCARDE et al., 1992). Neste sentido, como a uréia utilizada neste trabalho, após ter sido retirada da embalagem oriunda da indústria de fertilizante, ficou exposta às condições do ambiente durante a instalação do experimento, pode ter absorvido a umidade atmosférica. Exemplificando, a umidade crítica da uréia é de 75,2\% (TVA, 1970), significando que este fertilizante já absorverá umidade com relativa intensidade quando a umidade relativa do ar for igual ou maior que 75,2 (ALCARDE et al., 1989), o que é comum nas condições amazônicas. Ressalta-se que Alcarde et al. (1992) constaram até $18,46 \%$ de umidade absorvida pela uréia, considerando a umidade relativa de $88,8 \%$.

Assim, durante o período de contato das sementes com o adubo em saco plástico fechado, o fertilizante pode ter transferido o excedente de água para as sementes. Com o aumento do tempo de contato do fertilizante com as sementes (Tabela 1; Figura 1A) houve o aumento do teor de água das sementes, chegando nos dois últimos tratamentos a dobrar o teor de água quando comparados à testemunha. Comportamento semelhante foi constatado no trabalho de Dan et al. (2011), quanto ao teor de água, onde os valores percentuais foram aumentando com o transcorrer do tempo de contato, seguindo um comportamento exponencial.

A taxa de absorção de água pelas sementes depende de uma diferença de potencial hídrico entre a semente e o meio circundante (DANTAS et al., 2003), que no caso do presente experimento foi a uréia.

Tabela 1. Teor de água, germinação, primeira contagem e condutividade elétrica (CE) de sementes de Brachiaria brizantha cv. Marandú em função do tempo de mistura com o fertilizante granulado Uréia.

\begin{tabular}{ccccc}
\hline Tempo de & Teor de & \multicolumn{3}{c}{ Primeira } \\
Mistura (T) & Água & Germinação & Contagem & $\mathrm{CE}$ \\
\hline (horas) & $(\%)$ & $(\%)$ & $(\%)$ & $\left(\mu \mathrm{S} \mathrm{cm}^{-1} \mathrm{~g}^{-1}\right)$ \\
0 & $10,5 \mathrm{~g}$ & $57,0 \mathrm{a}$ & $55,0 \mathrm{a}$ & $100,9 \mathrm{~d}$ \\
3 & $13,0 \mathrm{f}$ & $43,5 \mathrm{~b}$ & $42,0 \mathrm{~b}$ & $549,6 \mathrm{c}$ \\
6 & $15,4 \mathrm{e}$ & $18,0 \mathrm{c}$ & $17,0 \mathrm{c}$ & $538,8 \mathrm{c}$ \\
12 & $16,4 \mathrm{~d}$ & $11,5 \mathrm{~d}$ & $10,0 \mathrm{~d}$ & $549,1 \mathrm{c}$ \\
24 & $15,8 \mathrm{de}$ & $8,0 \mathrm{~d}$ & $6,5 \mathrm{~d}$ & $552,3 \mathrm{bc}$ \\
36 & $16,4 \mathrm{~d}$ & $5,5 \mathrm{de}$ & $5,5 \mathrm{de}$ & $609,9 \mathrm{bc}$ \\
48 & $17,5 \mathrm{c}$ & $0,5 \mathrm{e}$ & $0,5 \mathrm{e}$ & $733,0 \mathrm{ab}$ \\
72 & $19,3 \mathrm{~b}$ & $0,5 \mathrm{e}$ & $0,5 \mathrm{e}$ & $817,6 \mathrm{a}$ \\
96 & $20,1 \mathrm{a}$ & $0,0 \mathrm{e}$ & $0,0 \mathrm{e}$ & $688,2 \mathrm{abc}$ \\
120 & $20,1 \mathrm{a}$ & $0,0 \mathrm{e}$ & $0,0 \mathrm{e}$ & $700,7 \mathrm{abc}$ \\
Valor de F & $454,9 * *$ & $257,0^{* *}$ & $274,3 * *$ & $26,4 * *$ \\
\hline CV $(\%)$ & 1,2 & 17,3 & 17,1 & 13,0 \\
\hline
\end{tabular}

Médias seguidas de mesma letra, na coluna, não diferem entre si a 5\% pelo teste de Tukey. ${ }^{* *}$ significativo a $1 \%$ pelo teste F. 

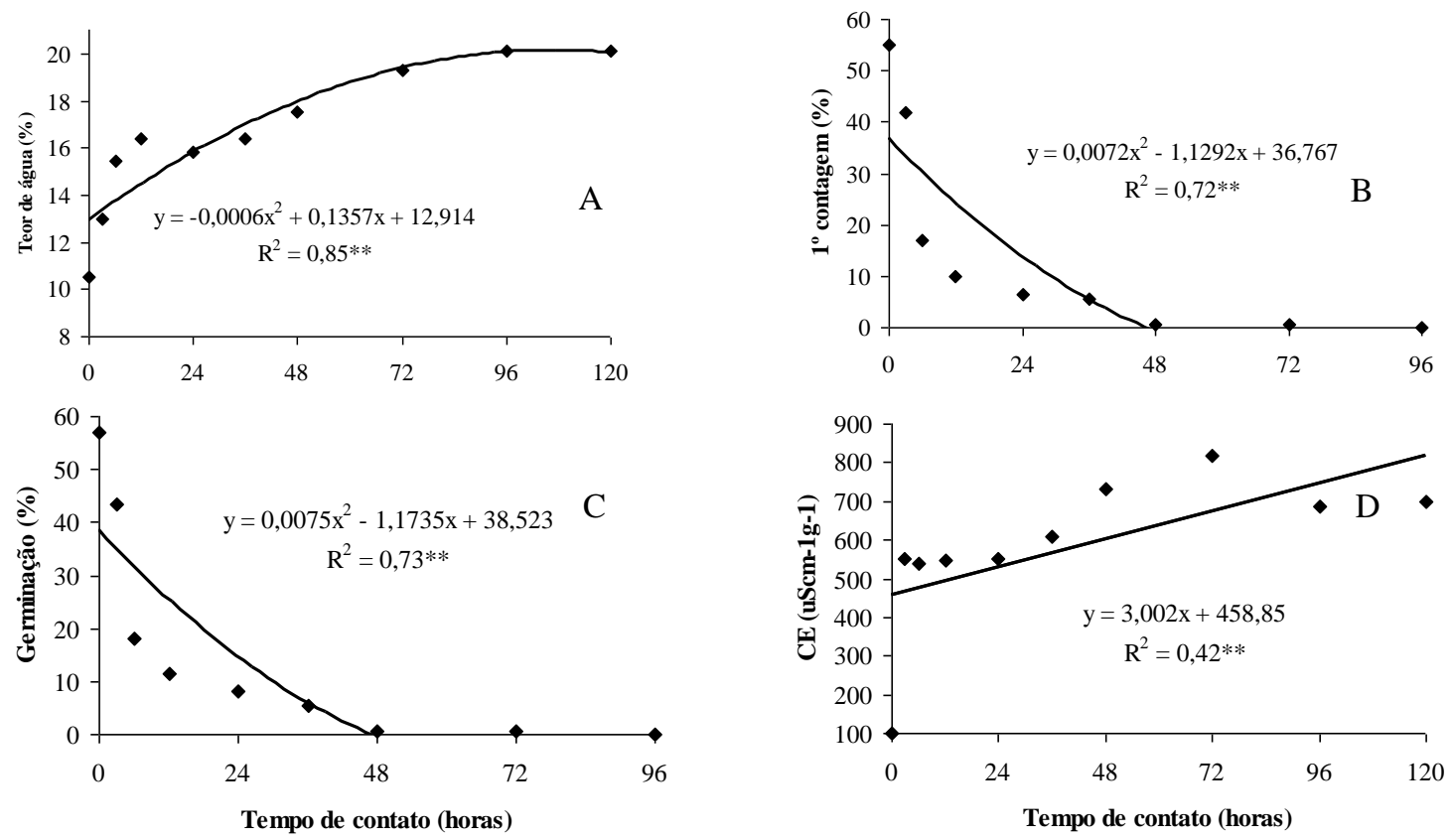

Figura 1. Teor de água (A), primeira contagem (B), germinação (C) e condutividade elétrica (D) de sementes de Brachiaria brizantha cv. Marandú em função do tempo de contato com o fertilizante granulado uréia.

Desta forma, quanto maior o teor de água disponível no meio circundante, mais água será transferida para as sementes.

A hidratação muito rápida, causada pelas diferenças muito acentuadas entre os potenciais hídricos das sementes e do substrato (uréia), acarretam a entrada muito rápida de água nas sementes, ocasionando o chamado dano por embebição, que leva à perdas de grandes quantidades de exsudatos e ruptura da estrutura celular (MARCOS FILHO, 2005). As sementes mais secas, com teores de água inferiores a 11\%, como verificado no presente trabalho (Tabela 1), são mais sensíveis a estas injúrias (MARCOS FILHO, 2005).

A hidratação das sementes em mistura com a uréia, em função da elevada higroscopicidade do adubo, caracteriza o início do processo de embebição, onde a água apresenta a grande função de amolecer o tegumento, diminuindo a integridade do mesmo e desorganizando a sua estrutura (MARCOS FILHO, 2005). Este rompimento do tegumento resultará em um aumento na lixiviação de solutos, tais como açúcares, aminoácidos, ácidos orgânicos, proteínas, substâncias fenólicas e de íons inorgânicos, o que caracteriza sementes com baixo vigor (VANZOLINI; NAKAGAWA, 2003; DIAS et al., 2006).

Os estágios iniciais da hidratação da semente caracterizam um período em que a semente muda de um estado praticamente anidro para outro completamente hidratado, capaz de se desenvolver e de responder a estímulos do ambiente (MARCOS FILHO, 2005). A hidratação das sementes, mesmo que parcial, além do amolecimento do tegumento, inicia o processo físiológico de germinação, intensificando a velocidade respiratória e favorecendo as trocas gasosas (DANTAS et al., 2003; MARCOS FILHO, 2005). Portanto, o embrião para crescer e romper o tegumento necessita absorver água para desenvolver os processos iniciais de divisão e expansão celular (DANTAS et al., 2003). Também, as enzimas responsáveis 
pela germinação são ativadas pela presença da água, como a $\alpha$-amilase (TAIZ; ZEIGER, 2006).

Knott (1957) foi quem alertou, pela primeira vez, sobre a salinização provocada pelos fertilizantes minerais, principalmente os potássicos e nitrogenados, apresentando a úreia 75,4 de índice salino. Os fertilizantes nitrogenados são sais, que podem proporcionar efeitos tóxicos pela elevação da concentração de íons no embrião das sementes (AGOSTINETTO et al., 2000; DANTAS et al., 2003). A salinidade também pode ter contribuído para redução do percentual de germinação no presente trabalho, em função do efeito tóxico dos sais sobre os tecidos vivos das sementes em processo inicial de germinação, especialmente penetrando até o eixo embrionário, o qual possui células bastante sensíveis (DANTAS et al., 2003). Portanto, o estresse salino, causador da toxidez, induzida pelo manejo (mistura de sementes + uréia), é um fator progressivo e contínuo de distúrbios fisiológicos no embrião das sementes, afetando, consequentemente, a formação do estande e, em última análise, a produção.

$\mathrm{O}$ vigor reflete a manifestação de um conjunto de características que determinam o potencial para a emergência rápida $\mathrm{e}$ uniforme de plântulas normais sob ampla diversidade de condições ambientais (MARCOS FILHO, 2005). O uso de testes de vigor é uma ferramenta imprescindível para a avaliação do potencial fisiológico dos lotes de sementes (VIEIRA; KRZYZANOWSKI, 1999). Um teste de vigor que tem se mostrado eficiente é o teste de condutividade elétrica proposto como um parâmetro de avaliação bioquímica do vigor das sementes de forma indireta (MARCOS FILHO, 2005).

O teste de condutividade elétrica é de rápida execução, objetivo e fácil de ser conduzido, além de não necessitar de muitos equipamentos e treinamento pessoal
(VIEIRA; KRZYZANOWSKI, 1999), estando incluído na Internacional Seed Testing Association (ISTA, 2006). O teste se baseia na integridade das membranas celulares (MARCOS FILHO, 2005), tendo como objetivo avaliar a intensidade dos danos causados ao tegumento das sementes, em função de algum processo de deterioração (VANZOLINI; NAKAGAWA, 2003; DIAS et al., 2006).

Avaliando-se a condutividade elétrica das sementes de $B$ brizantha em função do tempo de contato com a uréia, verificou-se que a testemunha foi o tratamento com o menor valor para esta variável, sendo que com o transcorrer do tempo de contato os valores de condutividade foram aumentando de forma linear como apresentado (Tabela 1; Figura 1D). $O$ teste realizado avalia a condutividade elétrica de uma solução, por meio da quantificação dos solutos lixiviados pela semente na água de embebição.

Sementes com qualidade inferior terão uma condutividade elétrica maior que sementes de qualidade superior, em consequência de menor permeabilidade seletiva da membrana, liberando maiores quantidades de lixiviados na água de embebição. (POWELL, 1995). Dessa forma, o vigor das sementes é considerado inversamente proporcional ao valor da condutividade elétrica (VIEIRA; KRZYZANOWSKI, 1999).

Quanto aos testes de vigor, emergência e índice de velocidade de emergência (IVE), conduzidos em viveiro, foi verificado que tanto para emergência como para o IVE houve efeito significativo dos tratamentos (Tabela 2).

Resultado similar foi observado por Dan et al. (2011), onde a redução tanto na emergência quanto no IVE ocorreu conforme houve o aumento no tempo de mistura fertilizante + semente. 
Tabela 2. Emergência e índice de velocidade de emergência (IVE) de sementes de Brachiaria brizantha da cultivar Marandú, em função do tempo de mistura com o fertilizante granulado Uréia.

\begin{tabular}{ccc}
\hline Tempo de Mistura & \multicolumn{2}{c}{ Semeadura (semente) } \\
\cline { 2 - 3 }$(\mathrm{T})$ & Emergência & IVE \\
\hline (horas) & $(\%)$ & $79,0 \mathrm{a}$ \\
0 & $45,5 \mathrm{a}$ & $54,7 \mathrm{~b}$ \\
3 & $32,0 \mathrm{~b}$ & $50,7 \mathrm{~b}$ \\
6 & $30,0 \mathrm{bc}$ & $57,2 \mathrm{ab}$ \\
12 & $31,0 \mathrm{bc}$ & $54,4 \mathrm{~b}$ \\
24 & $26,0 \mathrm{bcd}$ & $37,1 \mathrm{bc}$ \\
36 & $20,5 \mathrm{cde}$ & $34,5 \mathrm{bc}$ \\
48 & $18,0 \mathrm{de}$ & $19,0 \mathrm{~cd}$ \\
72 & $10,0 \mathrm{ef}$ & $7,1 \mathrm{~d}$ \\
96 & $3,0 \mathrm{f}$ & $7,5 \mathrm{~d}$ \\
120 & $3,5 \mathrm{f}$ & $23,8^{* *}$ \\
Valor de F & $35,4^{* *}$ & 24,0
\end{tabular}

Médias seguidas de mesma letra, na coluna, não diferem entre si a 5\% pelo teste de Tukey. ** significativo a $1 \%$ pelo teste F.

Houve similaridade de comportamento observado pela diminuição gradual na percentagem de emergência e de IVE na medida em que se aumentou o tempo de contato do adubo com as sementes (Tabela 2 e Figura 2), semelhante ao comportamento verificado para a primeira contagem e germinação (Tabela 1 e Figura 1).

Todavia, os percentuais de emergência das plântulas de $B$. brizantha em viveiro, somente nos dois primeiros tratamentos ( 0 e $3 \mathrm{~h}$ de mistura) apresentaram valores menores em relação aos obtidos no laboratório (germinação). Em contrapartida, os demais valores de emergência foram maiores do que os obtidos pelo teste de germinação. Mateus et al. (2007) também verificaram comportamento distinto entre o efeito da uréia em contato com as sementes em condição de laboratório (germinação) e no campo (emergência).

A adição de uréia ao solo e sua hidrólise proporciona inicialmente a elevação do $\mathrm{pH}$ ao redor dos grânulos do fertilizante (ERNANI, 2008), e converte todo seu conteúdo em $\mathrm{NH} 4+$, que reage com a $\mathrm{OH}-$ formando $\mathrm{H} 2 \mathrm{O}$ e $\mathrm{NH} 3$ que é volátil e tóxico (OUYANG et al., 1998; ERNANI et al., 2001).

Ressalta-se que após a separação das sementes misturadas ao adubo, não houve lavagem das mesmas. Neste procedimento, resíduos do fertilizante uréia puderam permanecer aderidos ao tegumento das sementes.

Estes resíduos mantidos em umidade próxima a $100 \%$ em caixas de gerbox junto às sementes no laboratório, ou acrescidos dos teores de $\mathrm{N}$ já presentes no solo úmido em viveiro, podem ter rapidamente se hidrolisado. Isto produziria um excesso de $\mathrm{NH}_{3}$ liberado, responsável por provocar efeito tóxico (KLUTHCOUSKI et al., 2006) adicional, além da salinidade, contribuindo negativamente para o processo de germinação das sementes e emergência das plântulas (AGOSTINETTO et al., 2000). 

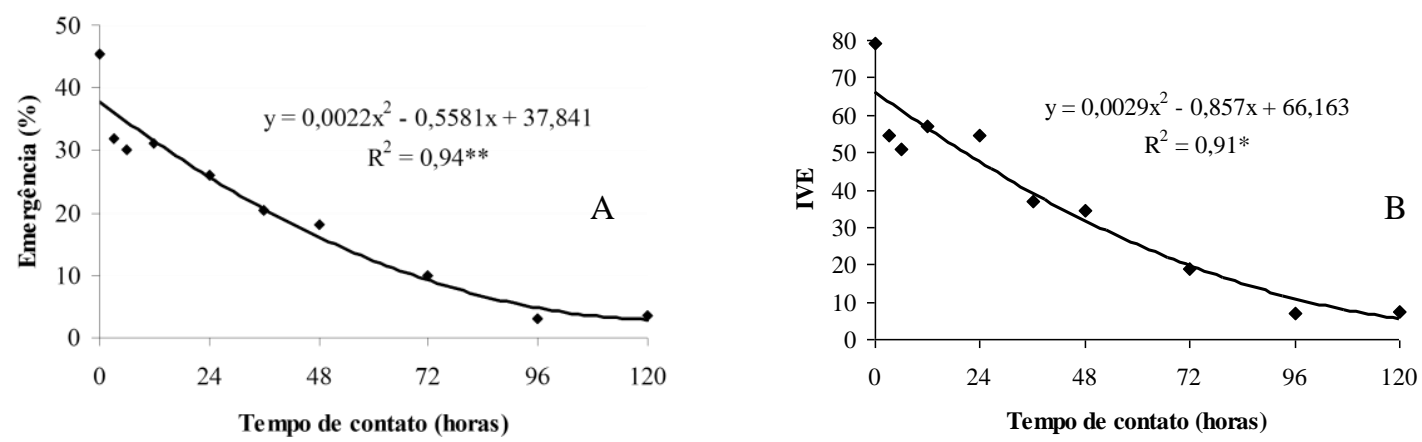

Figura 2. Emergência (A) e índice de velocidade de emergência (B) de plântulas de Brachiaria brizantha cv. Marandú em função do tempo de contato com o fertilizante granulado uréia.

Deve-se considerar como aceitável para B. brizantha cv. Marandú uma germinação próxima de 60\% (PERES et al., 2012), fato este verificado apenas no tratamento controle (Tabela 1). Dan et al. (2011) concluíram que há viabilidade na mistura das sementes de B. ruziziensis com o fertilizante nitrogenado, desde que a semeadura fosse efetuada em intervalo de tempo inferior a $8 \mathrm{~h}$, reduzindo-se os danos à qualidade fisiológica das sementes da forrageira.

Todas as variáveis indicam que as sementes de Brachiaria brizantha cv. Marandú, misturadas com o fertilizante granulado uréia, devem ser semeadas imediatamente, para não haver injúrias que reduzam substancialmente a germinação e o vigor. Assim, para que a perda na qualidade fisiológica não prejudique a formação do estande, a mistura de sementes de $B$. brizantha com a uréia deve ser feita, sempre que possível, de forma imediata à semeadura, com intervalo de tempo inferior a $3 \mathrm{~h}$.

\section{CONCLUSÃO}

Nas condições estudadas, quanto maior o tempo de contato das sementes de Brachiaria brizantha cv. Marandú com o fertilizante uréia, menor será a taxa de germinação e vigor.

\section{REFERÊNCIAS BIBLIOGRÁFICAS}

AGOSTINETTO, D.; FLECK, N.G.; VIDAL, R.A.; MEROOTTO JÚNIOR, A. 2000. Efeitos de adubos nitrogenados aplicados ao solo na germinação de sementes de plantas daninhas. Rev. Bras. de Agrociência, v.6, 200-205.

AIDAR, H.; KLUTHCOUSKI, J. Evolução das atividades lavoureira e pecuária nos cerrados. In: KLUTHCOUSKI, J.; STONE, L.F.; AIDAR, H. 2003. Integração lavoura-pecuária. Santo Antônio de Goiás: Embrapa Arroz e Feijão, p. 25-58.

ALCARDE, J.C.; GUIDOLIN, J.A.; LOPES, A.S. 1989. Os adubos e a eficiência das adubações. São Paulo, Anda, 35p. (Boletim Técnico, 3)

ALCARDE, J.C.; MALAVOLTA, E.; BORGES, A.L.; MUNIAZ, A.S.; VELOSO, C.A.; FABRÍCIO, A.C.; VIEGAS, I. de J.M. 1992. Avaliação da higroscopicidade de fertilizantes e corretivos. Scientia Agricola, Piracicaba, v.49, p.137-144.

AOSA - ASSOCIATION OF OFFICIAL SEED ANALYSIS - AOSA. 1983. Seed vigour-testing handbook. East Lansing: AOSA, 85p.

BACCHI, O. 1974. Mistura de sementes de colonião (Panicum maximum Jacq.) com superfosfato. Sementes, n.1, p.38-40. 
BRASIL. Ministério da Agricultura e Reforma Agrária. 1992. Regras para análise de sementes. Brasília: SNAD/DNDV/CLAV. 365p.

DAN, H. A.; DAN, L.G. M.; BARROSO, A.L. L.; BRANCCINI, A. L.; PICCININ, G. G. 2011. Mistura de sementes de Brachiaria ruziziensis G.et E. com uréia visando a implantação do sistema de integração lavoura-pecuária. Revista Caatinga, Mossoró, v.24, p.68-73.

DANTAS, J.P.; FERREIRA, M.M.M.; MARINHO, F.J.L.; NUNES, M. S.A.; QUEIROZ, M.F.; SANTOS, P.T.A. 2003. Efeito do estresse salino sobre a germinação e produção de sementes de caupi. Agropecuária Técnica, Areia, v.24, p.119-130.

DIAS, D.C.F.S. BHERING, M.C.; TOKUHISA, D.; HILST, P.C. 2006. Teste de condutividade elétrica para avaliação do vigor em sementes de cebola. Revista Brasileira de Sementes, v.28, p.154-162.

EMBRAPA. Centro Nacional de Pesquisa de Gado de Corte. 2004. Forrageira: Brachiaria brizantha, cultivar Xaraés. Campo Grande: Embrapa.

EMPRESA BRASILEIRA DE PESQUISA AGROPECUÁRIA. 2006. Sistema Brasileiro de Classificação de Solos. Rio de Janeiro: Embrapa - CNPS, 306 p. ERNANI, P. R. 2008. Química do solo e disponibilidade de nutrientes. Graphel, Lages, Brasil, 230p.

ERNANI, P. R.; BAYER, C.; STECKLING, C. 2001. Características químicas de solo e rendimento de matéria seca de milho em função do método de aplicação de fosfatos, em dois níveis de acidez. Revista Brasileira de Ciência do Solo, Viçosa-MG, v.25, p.939-946.

FOLONI, J.S.S.; CUSTÓDIO, C.C.; CALDEIRA, F.J.; CALVO, C.L. 2009. Emergência de plântulas de Brachiaria brizantha influenciada por escarificação das sementes, uso de adubo e profundidade de semeadura. Científica, v.37, p.89-97.

ISTA. 2006. International Seed Testing Association. International rules for testing seeds. Seed Science and Technology, 32:403.

JANEGITZ, M.C.; HERMANN, E.R. 2011. Fontes e concentração de nitrogênio no desenvolvimento inicial de plântulas de feijão. Cultivando o Saber, Cascavel, v.4, n.3, p.180-188.

KLUTHCOUSKI, J.; AIDAR, H.; THUNG, M.; OLIVEIRA, F.R.A.; COBUCCI, T. 2006. Manejo antecipado do nitrogênio nas principais culturas anuais. Santo Antônio de Goiás: Embrapa Arroz e Feijão, 63p. (Documentos / Embrapa Arroz e Feijão, 188)

KNOTT, J. E. Handbook for vegetable growers. 1957. London: J. Wiley, 238 p.

LIMA, E. V.; CAVARIANI, C.; LIMA, P. L; CRUSCIOL, C.A.C.; NAKAGAWA, J.; VILLAS BOAS, R.L. 2000. Qualidade fisiológica de sementes de painço (Panicum dichotomiflorum Mix.) em função do tempo de mistura com o superfosfato triplo. Cultura Agronômica, Ilha Solteira, v.9, p.177189.

LIMA, E. V.; TAVARES, J.C. S.; SILVA, E.C.; LIMA, P. S.L. 2009. Superfosfato triplo como via de distribuição de sementes de Brachiaria. Revista Brasileira de Zootecnia, Viçosa, v.38, p.796-800.

LIMA, E. V.; TAVARES, J.C. S.; AZEVEDO, V.R.; LIMA, P. S.L. 2010. Mistura de sementes de Brachiaria brizantha com fertilizante NPK. Ciência Rural, v.40, p.471-474.

LIMA, E. V.; TAVARES, J.C. S.; LIMA, P. S.L.; PINHEIRO, D.P.; FERNANDES, A.R. 2012. Segregação física de sementes de braquiária com fertilizante NPK na simulação de semeadura com matraca. Revista de Ciências Agrárias, v.55, p.338-342. 
MARCOS FILHO, J. Fisiologia de sementes de plantas cultivadas. 2005. Piracicaba, Fealq, 495p.

MAGUIRE, L. D. 1962. Speed of germination - aid in selection and evolution for seedling emergence and vigor. Crop Science, Madison, v.2, p 176-177.

MATEUS, G.P.; BORGHI, E.; MARQUES, R.R.; VILLAS BÔAS, R.L.; CRUSCIOL, C.A.C. 2007. Efeito de fontes e períodos de contato de fertilizantes em sementes de Brachiaria brizantha. Revista Brasileira de Ciências do Solo, Viçosa-MG, v. 31, p. 177-183.

MELLO, F. A. F. Uréia fertilizante. 1987. Campinas, Fundação Cargill, 192p.

MOREIRA, W.H.; BETIOLI JUNIOR, E.; PETEAN, L.P.; TORMENA, C.A.; ALVES, S.J.; COSTA, M.A.T.; FRANCO, H.H.S. 2012. Atributos físicos de um latossolo vermelho distroférrico em sistema de integração lavourapecuária. Revista Brasileira de Ciência do Solo, Viçosa-MG, v.36, p.389-400.

OUYANG, D.; MACKENZIE, A. F.; Fan, M. 1998. Phytotoxicity of banded urea amended with triple superphosphate and potassium chloride. Agronomy Journal, v.90, p.734-739.

PERES, A.R.; VAZQUEZ, G.H.; CARDOSO, R.D. 2012. Physiological potential of Brachiaria brizantha cv. Marandú seeds kept in contact with phosphatic fertilizers. Revista Brasileira de Sementes, v.34, p.424-432.

POWELL, A. A. The Controlled Deterioration Test. 1995. In: INTERNATIONAL SEED TESTING ASSOCIATION. Seed Vigour Testing Seminar. Zurich, p.73-87.

RAIJ, B. van.; CANTARELLA, H.; QUAGGIO, J. A.; FURLANI, A.M.C. 1997. Recomendações de adubação e calagem para o estado de São Paulo. 2. ed. Campinas: Instituto Agronômico e Fundação IAC. (Boletim Técnico, 100).

SANGOI, L.; ERNANI, P. R.; BIANCHET, P. 2009. Desenvolvimento inicial do milho em função de doses e fontes de nitrogênio aplicadas na semeadura.

Revista Biotemas, v.22. p.53-58.

SANGOI, L.; ERNANI, P. R.; SILVA, P. R. F. 2007. Maize response to nitrogen fertilization timing at two tillage systems in a soil with high organic matter content. Revista Brasileira de Ciência do Solo, Viçosa-MG, v.31, p.507-517.

SILVA, G. M.; STONE, L. F.; MOREIRA, J. A. A. 2002. Manejo da adubação nitrogenada no feijoeiro irrigado sob plantio direto. Pesquisa Agropecuária Tropical, Goiânia, v. 32, p.1-5.

SORATTO, R.P.; LIMA. E. V.; MAUAD, M.; VILLAS BÔAS, R. L.; NAKAGAWA，J. 2003. Millet seeds mixed whit phosphate fertilizers. Scientia Agricola, Piracicaba, v.60, p.573-579.

TAIZ, L.; ZEIGER, E. Plant Physiology. 4th ed. 2006. Cummings, Redwood City, USA, 608p.

T.V.A. Procedures for determinning physical properties of fertilizers. Special Repor n. 5.444. September, 1970. 17p, Tennessee Valley Authority, Mucle Shoals, Alabama, USA.

VANZOLINI, S.; NAKAGAWA, J. 2003. Lixiviação de potássio na avaliação da qualidade fisiológica de sementes de amendoim. Revista Brasileira de Sementes, v.25, p.7-12.

VIEIRA, R. D.; KRZYZANOWSKI, F. C. Teste de condutividade elétrica. 1999. In: KRZYZANOWSKI, F. C.; VIEIRA, R. D.; FRANÇA NETO, J. B. (Ed.). Vigor de sementes: conceitos e testes. Londrina: ABRATES. Cap.4, p.1-26.

VITTI, G.; TAVARES JÚNIOR, J. E.; LUZ, P. H.; FAVARIN, J. L.; COSTA, M. C. G. 2002. Influência da mistura de sulfato de amônio com uréia sobre a 
volatilização de nitrogênio amoniacal. Revista Brasileira de Ciência do Solo, Viçosa-MG, v.26, p.663-671

Recebido em: 4/9/2013

Aceito para publicação em: 18/3/2014 